\title{
Optimization of in situ emplacement of nano-sized FeS for permeable reactive barrier construction
}

\author{
T. M. Olson \& J.-H. Lee \\ Department of Civil and Environmental Engineering, \\ University of Michigan, Ann Arbor, Michigan, USA
}

\begin{abstract}
Construction techniques for permeable reactive barriers (PRBs) have commonly involved trench-and-fill methods. These strategies, however, are limited in use to shallow groundwater remediation applications. To extend the technology to deeper, less accessible zones of contamination, in situ emplacement methods of the reactive media are required. In this paper, development studies of an in situ PRB construction method are presented that rely on the injection and deposition of nano-sized iron sulphide particles. Optimal chemical conditions for depositing FeS particles in sand bed media were ascertained that maximize surface coatings and minimize reductions in hydraulic conductivity. Our studies indicate that moderately alkaline injection conditions are needed to establish optimal coverage of $\mathrm{FeS}$ on sand. The constraints necessitating these chemical conditions are discussed in terms of FeS surface charge characteristics and particle filtration theory.

Keywords: permeable reactive barriers, iron minerals, construction methods, trace metals, particle deposition, metal sulphides, zero valent iron, groundwater remediation.
\end{abstract}

\section{Introduction}

Permeable reactive barriers (PRBs) have been applied with increasing frequency as a technology to clean up or manage groundwater contamination. Such passive, in situ methods of treatment and/or immobilization of contaminants offer a potentially economically attractive option for this type of waste management. Among the many reactive media which have been used, granular forms of zero 
valent iron (ZVI) are the most common, comprising at least $45 \%$ of the media in PRB applications [1]. The use of economical sources of ZVI, however, is limited to trench-and-fill PRB construction methods and relatively shallow installations. Deeper aquifer environments, however, are more likely to present the desired anoxic conditions that are required for an effective PRB, but methods to construct PRBs for these locations are lacking. An in situ method of PRB construction involving the injection and deposition of colloidal reduced iron minerals on native subsurface materials has been examined in this study. Iron sulphide was selected as the reactive media since it can be readily synthesized as a nano-sized colloidal suspension and because it is a versatile sequestering agent for many contaminants.

\section{FeS media properties}

\subsection{Reactivity}

Iron sulphide minerals have a high capacity to sequester 1) non-redox active metals by forming insoluble metal sulphides, and 2) redox-active metals, by reduction first, followed by precipitation of the reduced metal as mixed metal sulphide solid. Redox active metals such as $\mathrm{As}(\mathrm{V})$ for example, can be reduced by FeS to $\mathrm{As}(\mathrm{III})$ and precipitated as the solid orpiment $\left(\mathrm{As}_{2} \mathrm{~S}_{3}\right)$ [2]. Although the reactivity of a FeS barrier would ultimately degrade as FeS is converted to other sulphide minerals, opportunities to microbially regenerate FeS surfaces are possible. Sulfate reducing bacteria can oxidize organic matter and reduce sulfate to sulphide and produce $\mathrm{FeS}$ if sufficient reduced iron is present. Such microbially mediated FeS production has been shown to produce mackinawite (FeS) [3]. Based on the versatile metal ion sequestration potential and the novel biogenic opportunities for $\mathrm{FeS}$ regeneration, the media was selected as the reactive barrier media for development of in situ emplacement methods.

\subsection{Nano-particle synthesis and characterization}

Nano-particulate FeS suspensions were prepared for use in this study in an anoxic chamber according to a method outlined by Butler and Hayes [4]. The resulting particles were harvested by centrifugation in tightly sealed bottles, sequential rinsing with deoxygenated distilled water, freeze-drying under vacuum, and storage of the dry powder in a nitrogen atmosphere. Powder X-ray diffraction analysis established that the mineral was a poorly crystalline mackinawite phase, with slightly greater-than-stoichiometric sulphur content. Photon correlation spectroscopy measurements of the re-suspended FeS, performed in an anoxic glovebox, revealed that the particles had a mean diameter of $3 \mathrm{~nm}$ that remained stable for over two hours.

Based on the synthesis method, the ambient $\mathrm{pH}$ of the resuspended nanoparticles in distilled water was relatively alkaline. Preparation of a $1 \mathrm{~g} / \mathrm{L} \mathrm{FeS}$ suspension in distilled water, for example, yielded a solution $\mathrm{pH}$ of 10.3. Borate buffer and/or $\mathrm{HCl}$ were required to establish more circumneutral $\mathrm{pH}$ conditions 
in column experiments. From literature studies the FeS point of zero charge, $\mathrm{pH}_{\mathrm{pzc}}$, i.e., the $\mathrm{pH}$ at which positive and negatively charged surface groups are equal in concentration, appears to be relatively uncertain. Some reports indicate its $\mathrm{pH}_{\mathrm{pzc}}$ may be as low as 3 [5]. The nanoparticulate $\mathrm{FeS}$ used in this study may be significantly less acidic, however. Unpublished electroacoustic characterizations of $\mathrm{FeS}$ surface charge by another research group, using the same synthesis method used herein, indicate its $\mathrm{pH}_{\mathrm{pzc}}$ is about 5 [6]. Over the $\mathrm{pH}$ range of most groundwater environments, the $\mathrm{FeS}$, therefore, would have an overall negative surface charge.

\section{FeS deposition experiments in sand columns}

\subsection{Column description and apparatus}

The deposition of FeS particles was studied as a function of solution chemistry in packed columns of clean quartz sand. Prior to use, the sand (mean diameter approximately $175 \mu \mathrm{M}$ ) was treated with sequential rinses of sodium dithionite and hydrogen peroxide solutions to remove metals and organics. The sand packed columns, $2.6 \mathrm{~cm}$ in diameter and $25 \mathrm{~cm}$ in length, had an average porosity of 0.34. A schematic diagram of the column experiment apparatus is shown in Figure 1.

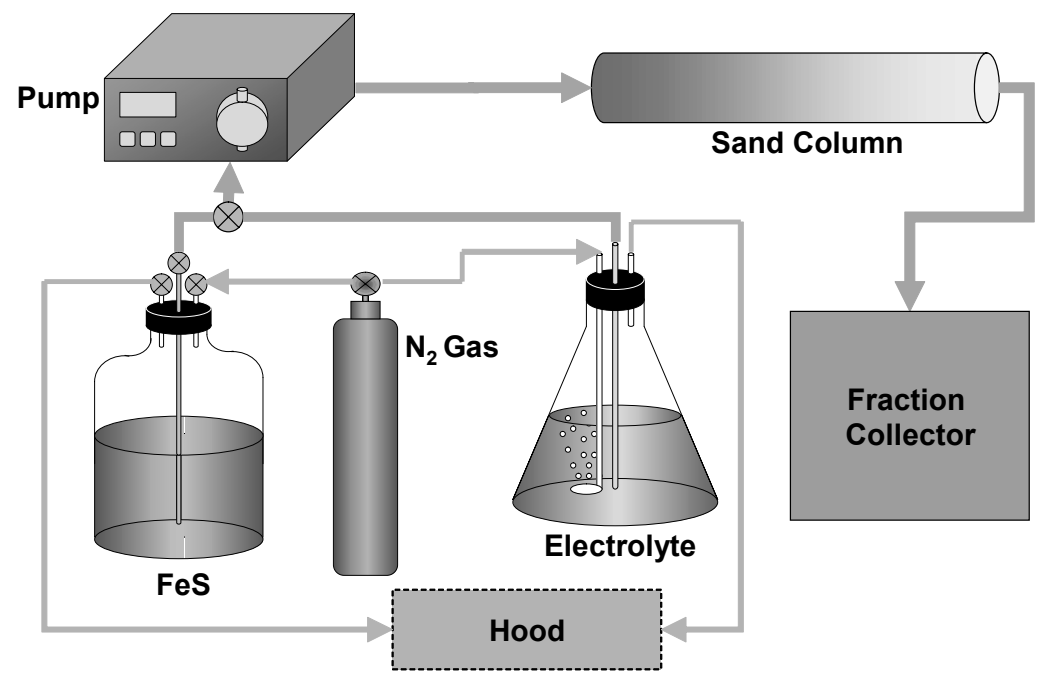

Figure 1: Schematic diagram of column apparatus.

\section{2 $\mathrm{FeS}$ injection experiment and analysis procedures}

Prior to injection of the FeS, the sand media was initially equilibrated with two pore volumes of the background electrolyte. To minimize oxidation, the influent 
$1 \mathrm{~g} / \mathrm{L} \mathrm{FeS}$ suspension was maintained under a nitrogen atmosphere while it was pumped through the sand column. Ten pore volumes of the suspension were processed in each experiment. Borate buffers and $\mathrm{HCl}$ were used to adjust and fix the $\mathrm{pH}$ of the suspension over the range of 8.2 to 10.3. Sodium chloride was added to adjust the ionic strength.

During the FeS deposition experiments, column effluent samples were collected in a fraction collector and analyzed by ICP-MS for their iron content. After the experiment, two pore volumes of the background electrolyte were applied to remove any suspended particles, the sand was sectioned by hydraulic extrusion, and the deposited FeS concentrations on the sand were determined by extraction of the iron in strong acid, and iron analysis by ICP-MS.

\subsection{Results and data analysis}

Chemical electrolyte conditions were selected on the basis of particle stability and $\mathrm{pH}$ buffering requirements. The solution $\mathrm{pH}$ range considered, $\mathrm{pH} 8.2$ to 10.3, was determined at the acidic end of the range by the stability of a $1 \mathrm{~g} / \mathrm{L} \mathrm{FeS}$ suspension. At $\mathrm{pH}$ conditions below 8.2, the suspensions were observed to aggregate significantly. The ionic strength range used in the column experiments was similarly determined by suspension stability and $\mathrm{pH}$ buffer requirements. The minimum ionic strength when buffers were added was approximately $0.025 \mathrm{M}$. The maximum ionic strength used was $0.05 \mathrm{M}$, due to suspension instability at higher salt contents.

$$
\begin{aligned}
& -\mathrm{pH} 10.3, \text { lonic Strength }=50 \mathrm{mM} \\
& -\mathrm{pH} 9.0, \text { lonic Strength }=24 \mathrm{mM} \\
& -\mathrm{pH} 8.2, \text { lonic Strength }=25 \mathrm{mM} \\
& -\mathrm{pH} 9.0, \text { lonic Strength }=50 \mathrm{mM}
\end{aligned}
$$

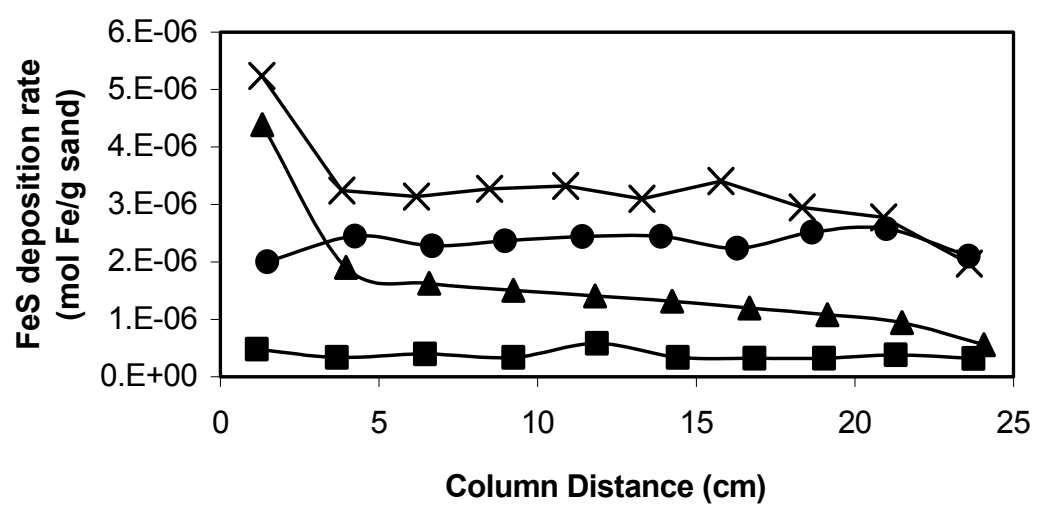

Figure 2: $\quad$ Effect of $\mathrm{pH}$ and ionic strength on deposited iron concentrations as a function of column depth after injecting 10 pore volumes of a $1 \mathrm{~g} / \mathrm{L} \mathrm{FeS}$ suspension. 
Profiles of the deposited FeS concentrations as a function of column depth are presented for a selected set of $\mathrm{pH}$ and ionic strength conditions in Figure 2. As these results indicate, optimum surface coverage was obtained at $\mathrm{pH} 9.0$, with $0.05 \mathrm{M}$ ionic strength. They furthermore suggest that deposited concentrations of the FeS throughout the column were reasonably uniform, although somewhat higher concentrations near the inlet were observed in some cases. Mean sand coverages and the fractional efficiency of FeS are reported in Table 1.

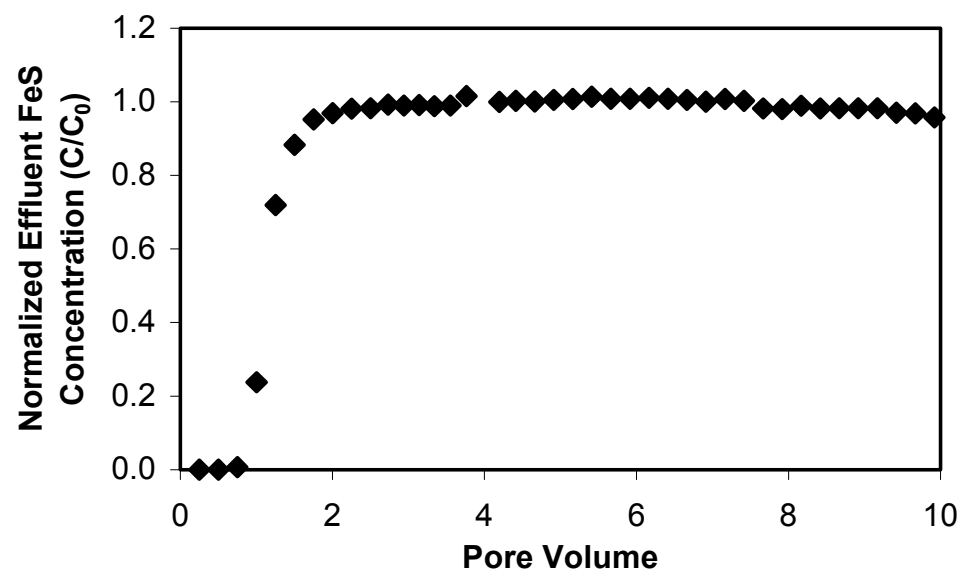

Figure 3: Effluent breakthrough curve deposition experiment conducted at $\mathrm{pH} 8.2$, ionic strength $=0.025 \mathrm{M}$.

Table 1: FeS coating concentrations and fractional deposition in sand column experiments.

\begin{tabular}{|ccccc|}
\hline & $\mathrm{pH} \mathrm{10.3,}$ & $\begin{array}{c}\mathrm{pH} 9.0, \\
\mathrm{I}=0.025 \mathrm{M}\end{array}$ & $\begin{array}{c}\mathrm{pH} \mathrm{9.0,} \\
\mathrm{I}=0.05 \mathrm{M}\end{array}$ & $\begin{array}{c}\mathrm{pH} 8.2, \\
\mathrm{I}=0.027 \mathrm{M}\end{array}$ \\
\hline $\begin{array}{c}\text { Coverage parameter } \\
\mathrm{I}=0.05 \mathrm{M}\end{array}$ & & & & \\
\hline $\begin{array}{c}\text { conc. (mole Fe } / \mathrm{g} \\
\text { sand) }\end{array}$ & $2.34 \mathrm{E}-06$ & $3.83 \mathrm{E}-07$ & $3.24 \mathrm{E}-06$ & $1.60 \mathrm{E}-06$ \\
$\begin{array}{c}\% \text { of injected FeS } \\
\text { deposited }\end{array}$ & $11.0 \%$ & $1.8 \%$ & $15.3 \%$ & $6.7 \%$ \\
\hline
\end{tabular}

In each of the experiments in Figure 2, particle breakthrough concentrations were also observed to be complete (i.e., effluent concentrations achieved a steady state concentration nearly equal to the influent concentration). A sample breakthrough curve illustrating this behaviour is shown in Figure 3 at $\mathrm{pH} \mathrm{8.2,}$ 
$\mathrm{I}=0.025 \mathrm{M} . \quad$ The achievement of complete breakthrough suggests that interactions of depositing particles with the coated sand media are sufficiently unfavourable (electrostatically repulsive) and that saturation FeS coverage of surface is obtained.

Attempts to emplace FeS particles at $\mathrm{pH} 8.2$ at a higher ionic strength of $0.05 \mathrm{M}$, however, resulted in incomplete particle breakthrough and eventual plugging of the column inlet region. Influent suspensions at these electrolyte conditions were also relatively unstable. Given the instability of the suspensions at $\mathrm{pH}<8.2$ in the presence of modest concentrations of background electrolyte, the $\mathrm{FeS}$ surface $\mathrm{pH}_{\mathrm{pzc}}$ is likely to be closer to the more weakly acidic values discussed above.

\section{Conclusions and implications}

To achieve relatively uniform FeS sand coverage across a PRB zone and avoid inlet plugging during emplacement, requires chemical conditions that are moderately alkaline $(\mathrm{pH}>8.2)$ and relatively low in ionic strength $\left(\mathrm{I}_{\max }=0.05\right.$ $\mathrm{M})$. Under these conditions, $\mathrm{FeS}-\mathrm{FeS}$ interactions are sufficiently unfavourable while FeS-sand interactions are sufficiently favourable. In many groundwater systems these alkaline conditions may not be practical, especially where an adjustment to an alkaline $\mathrm{pH}$ causes the precipitation of new solid phases. Additional strategies are needed therefore to extend the chemically feasible 'window' for FeS emplacement to lower pH. On-going research in our laboratory is focused on the development of such strategies.

\section{References}

[1] Scherer, M.M., Richter, S., Valentine, R.L. \& Alvarez, P.J.J., Chemistry and microbiology of permeable reactive barriers for groundwater clean up, Crit. Reviews in Environ. Sci. and Technol., 30(3), pp. 363-411, 2000.

[2] Rochette, E.A., Bostick, B.C., Li, G., \& Fendorf, S., Kinetics of arsenate reduction by dissolved sulphide, Environ. Sci. Technol., 34(22), pp. 47144710, 2000.

[3] Vaughan, D.J., \& Lennie, A.R., The iron sulphide minerals - Their chemistry and role in nature, Science Progress, 75(298), pp. 371-388, Part 3-4, 1991.

[4] Butler, E.C., \& Hayes, K.F. Effects of solution composition and $\mathrm{pH}$ on the reductive dechlorination of hexachlorethane by iron, Environ. Sci., Technol., 32(9), pp. 1276-1284, 1998.

[5] Bebie, J., Schoonen, A.A.M., Furhrmann, M., \& Strongin, D.R., Surface charge development on transition metal sulphides: An electrokinetic study, Geochimica Cosmochimica Acta, 62, pp. 633-642, 1998.

[6] Gallegos, T., Personal communication, 19 January 2006, Doctoral student, Civil \& Environ. Engineering, Univ. of Michigan, USA. 